\title{
Moving Fast-Scan Cyclic Voltammetry Towards FDA Compliance with Capacitive Decoupling Patient Protection
}

James R. Siegenthalera, Breanna C. Gushiken ${ }^{a}$, Daniel F. Hill ${ }^{b}$, Stephen L. Cowen ${ }^{b, d}$, and Michael L. Heiena,*

a Department of Chemistry \& Biochemistry, University of Arizona, Tucson, AZ, USA

${ }^{b}$ Department of Physiology, University of Arizona, Tucson, AZ, United States

${ }^{c}$ Department of Psychology, University of Arizona, Tucson, AZ, United States

d Evelyn F. McKnight Brain Institute, University of Arizona, Tucson, AZ, USA

*To whom correspondence should be addressed:

1306 East University Boulevard

Tucson, AZ 85721

mheien@arizona.edu

phone:520-621-6293

FAX: 520-621-8407 


\section{Table of Contents}

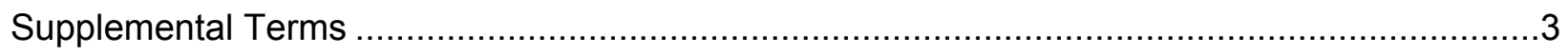

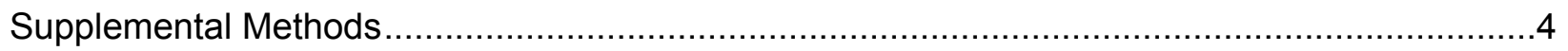

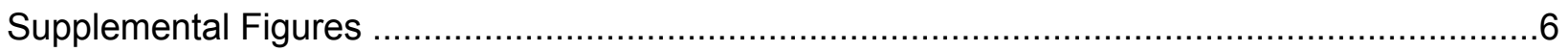

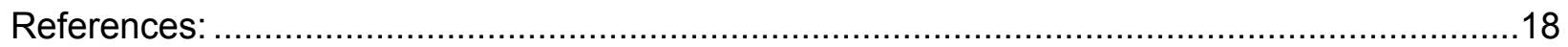

\section{Table of Figures}

Figure S-1: Comparison of the measured frequency response of the system from 1 to $10 \mathrm{kHz}$ with and without a $1200 \mathrm{pf}$ capacitor added in series to an electrode.

Figure S-2: Comparison of cross talk with and without voltage followers to probe the applied

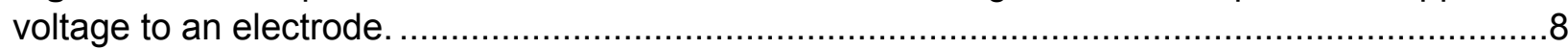

Figure S-3: Application and comparison of four different waveforms for measuring dopamine. .9 Figure S-4: Selected electrode backgrounds for four various waveforms investigated............11 Figure S-5: Dopamine measured with AC-coupled voltammetry comparing background changes. .12

Figure S-6: Effect of $\mathrm{pH}$ and $\left[\mathrm{Ca}^{2+}\right]$ on the measured current response. 13 Figure S-7: Comparison of [500 nM] dopamine and [100 $\mu \mathrm{M}]$ ferrocene carboxylic acid with different capacitor values.

Figure S-8: Application and comparison of the $400 \mathrm{~V} / \mathrm{s}$ waveform (Left) with the $1200 \mathrm{pF}$ ACcoupled charged balanced $1200 \mathrm{~V} / \mathrm{s}$ waveform (Right).

Figure S-9: Unfolded cyclic voltammograms of dopamine, serotonin (5-HT), 3,4Dihydroxyphenylacetic acid (DOPAC), and ascorbic acid comparing the standard dopamine waveform (Left) and the 1200 pf AC-coupled charged balanced $1200 \mathrm{~V} / \mathrm{s}$ waveform (Right). ...17 Figure S-10: Calibration curves of dopamine, 3,4-Dihydroxyphenylacetic acid (DOPAC), serotonin (5-HT) and ascorbic acid using $400 \mathrm{~V} / \mathrm{s}$ (red) and AC-coupled charge-balanced waveform with a $1200 \mathrm{pF}$ capacitor added in series (Blue). 


\section{Supplemental Terms}

To describe the response of the system we use the following definitions to help with clarity and to accurately convey what is occurring within the system. AC-coupling: Adding a capacitor in series with the working electrode to decouple the electrode from the voltage applied from the headstage. Interface voltage: The measured voltage at the working electrode vs. the reference electrode. Templet waveform: The desired voltage waveform at the working electrode. Input waveform: The calculated waveform based off the templet that is applied to the system. Applying the input waveform will generate the templet waveform at the working electrode interface. System frequency response: The system frequency response measured with a sine wave between the analog output of the NI card and the interface voltage of the electrode. Current is passed through the system, and the resulting voltage response of the sine wave is recorded as the frequency is varied. $400 \mathrm{~V} / \mathrm{s}$ waveform: A voltage sweep from $-0.4 \mathrm{~V}$ to $1.3 \mathrm{~V}$ to $-0.4 \mathrm{~V}$ at a rate of $400 \mathrm{~V} / \mathrm{s}$ used for standard FSCV measurements. $1200 \mathrm{~V} / \mathrm{s}$ waveform: A faster voltage sweep from $-0.4 \mathrm{~V}$ to $1.3 \mathrm{~V}$ to $-0.4 \mathrm{~V}$ at a rate of $1200 \mathrm{~V} / \mathrm{s}$. This waveform is similar to the FSCAV waveform but applied at $10 \mathrm{~Hz}$. Charge-balanced waveform: A voltage sweep that when integrated has a net voltage integral of $0 \mathrm{~V} \cdot \mathrm{s}$ resultant from a voltage sweep of $0 \mathrm{~V}$ to $-0.9 \mathrm{~V}$ to $1.3 \mathrm{~V}$ to $-0.9 \mathrm{~V}$ to $0 \mathrm{~V}$ at a rate of $1200 \mathrm{~V} / \mathrm{s}$. $A \boldsymbol{C}$ coupled charge-balanced waveform: The calculated waveform that uses a templet waveform voltage sweep from $0 \mathrm{~V}$ to $-0.9 \mathrm{~V}$ to $1.3 \mathrm{~V}$ to $-0.9 \mathrm{~V}$ to $0 \mathrm{~V}$ at a rate of $1200 \mathrm{~V} / \mathrm{s}$. The templet waveform when integrated has a net integral of $0 \mathrm{~V} \cdot \mathrm{s}$. The resulting calculated waveform is larger in amplitude than the templet, and when applied to the system yields the templet waveform at the interface voltage. 


\section{Supplemental Methods}

Chemicals. All chemicals were purchased from Sigma Aldrich (St. Louis, MO) unless otherwise noted. Sodium sulfate anhydrous and Sodium phosphate monobasic monohydrate were purchased from Mallinckrodt Baker, Inc. (Phillipsburg, NJ). Potassium chloride, sodium chloride, and sodium phosphate dibasic anhydrous were purchased from EMD Chemicals, Inc. (Gibbstown, NJ). Dopamine hydrochloride and serotonin hydrochloride were purchased from Alfa Aesar (Ward Hill, MA). Liquion Solution LQ-1105 1100EW (Nafion) was purchased from Ion Power, Inc. (New Castle, DE). Neurotransmitters were dissolved in $0.1 \mathrm{M} \mathrm{HClO}_{4}$ to make stock standards ranging from $1.0 \mu \mathrm{M}-200 \mu \mathrm{M}$. Artificial cerebral-spinal fluid (aCSF) was composed of $25 \mathrm{mM}$ Tris, $126 \mathrm{mM} \mathrm{NaCl}, 2.5 \mathrm{mM} \mathrm{KCl}, 1.2 \mathrm{mM} \mathrm{NaH}_{2} \mathrm{PO}_{4}, 2.0 \mathrm{mM} \mathrm{Na}_{2} \mathrm{SO}_{4}, 2.4 \mathrm{mM} \mathrm{CaCl}_{2}, 1.2$ $\mathrm{mM} \mathrm{MgCl} 2$, and adjusted to $\mathrm{pH}$ 7.4. The stock solutions of neurotransmitters for in vitro measurement were diluted in aCSF immediately prior to neurotransmitter measurement to prevent photo-induced oxidative degradation. ${ }^{1,2}$ Solution working time was kept to no greater than 30 min to prevent measurable differences caused by the oxidative degradation. Water used was purified using a MilliQ Gradient A10 water purification system (EMD, Millipore, Burlington, $\mathrm{MA}$ ) to a resistivity of $18.2 \mathrm{M} \Omega \cdot \mathrm{cm}$.

Microelectrode Fabrication. Carbon-fiber microelectrodes were fabricated and coated with PEDOT:Nafion as previously described. ${ }^{3,4}$ Briefly, a single AS4 carbon-fiber (Hexcel Corporation, Stamford, CT) was aspirated into a $0.68 \mathrm{~mm}$ ID single barrel glass capillary (1B120-4, World Precision Instruments, Inc., Sarsota, FL) and subsequently heated and pulled with a PE-2 pipette puller (Narishige, Japan). The exposed carbon fiber was trimmed to be $\sim 75 \mu \mathrm{m}$ from the edge of the glass seal under a microscope. Electrical connection was made using a wire (Kauffman Engineering, Cornelius, OR) coated with an alcohol-based graphite conductive adhesive (Alfa Aesar, Ward Hill, MA). Electrodes were then coated with PEDOT:Nafion using electrodeposition by cyclic voltammetry on a Gamry Instruments Reference 600 potentiostat (Warminster, PA). ${ }^{32}$ 
The coating procedure consisted of cycling from $+1.5 \mathrm{~V}$ to $-0.8 \mathrm{~V}$ against a silver quasi-reference at $100 \mathrm{mV} / \mathrm{s}$ for 15 cycles in a deposition solution consisting of $200 \mu \mathrm{M}$ EDOT and $200 \mu \mathrm{L}$ Nafion solution in $20 \mathrm{~mL}$ of dry acetonitrile. Reference electrodes used in all experiments were fabricated by soaking a silver wire $(0.25 \mathrm{~mm}$, Alfa Aesar $)$ in undiluted concentrated chlorine bleach overnight (Clorox Professional Products Company, Oakland, CA).

Flow-Injection System. Calibration and in vitro experiments were performed with a custombuilt flow injection analysis system using a pneumatically actuated six-port HPLC valve (Vici, Austin, TX). A solution flowrate of $0.5 \mathrm{~mL} / \mathrm{min}$ was controlled using a NE-1000 syringe pump (New Era Pump Systems, Inc., Farmingdale, NY). Flow-injection analysis was performed on dopamine, serotonin (5-HT), ascorbic acid, 3,4-Dihydroxyphenylacetic acid (DOPAC), ionic change, and $\mathrm{pH}$ change. All measurements were measured against a $\mathrm{Ag} / \mathrm{AgCl}$ quasi-reference electrode with a $10 \mathrm{~s}$ bolus injection within a $30 \mathrm{~s}$ recording window.

Anesthetized Animal Experiment. A male, Adult Sprague-Dawley rat (300 - 350 g, Harlan Laboratories, Harlan, Kentucky) was used. Rats were housed two per cage on a $12 \mathrm{~h}$ light-dark cycle with food and water provided ab libitum. Care of the animals was in accordance with the National Institutes of Health guidelines for laboratory animals and by the University of Arizona Institutional Animal Care and Use Committee. Stereotaxic surgeries were performed under isoflurane $(1.3-3 \%)$. Temperature of the animal was maintained at $37^{\circ} \mathrm{C}$ with a heating pad. Several small holes were drilled into the skull to access the nucleus accumbens and the ventral tegmental area (VTA) for carbon fiber electrode $(6.75 \mathrm{~mm})$ and stimulating electrode $(7.85 \mathrm{~mm})$ placement. The reference electrode was placed in the contralateral hemisphere $(3 \mathrm{~mm}, 3 \mathrm{~mm})$. A stimulating electrode (Plastics One, Wallingford, CT) was used to apply stimulation pulses to the VTA. The stimulation train consisted of 60 pulses applied at $60 \mathrm{~Hz}$, with $2 \mathrm{~ms}$ width, at $3 \mathrm{~V}$ pk-pk and a 70 ms delay to the application waveform was used to induce a dopamine release every $5 \mathrm{~min}$ from the VTA. 
Statistical Methods. Statistical data was calculated using GraphPad Version 5.01 (GraphPad Software Inc., La Jolla, CA, USA). A one-way analysis of variance (one-way ANOVA) with $95 \%$ confidence intervals with a post tests of Tukey's multiple comparison test. Statistical differences between two values was determined by a two tailed T-Test at the $95 \%$ confidence interval. A two tailed Mann-Whitney test was used at the 95\% confidence interval to determine statistical differences between means. Correlation coefficients were calculated using Microsoft Excel RSQ function to return the square of the Pearson product moment correlation coefficient. Correlation coefficient statistical analysis was done using COCOR for R programming language to calculate the Fisher Z-transformation with two sided test, alpha $=0.05$ and a 0.95 confidence interval. ${ }^{5}$ Values are reported as mean \pm standard deviation (sd) unless specified and $\mathrm{n}$ represents number of electrodes unless specified. 


\section{Supplemental Figures}

FFT of system measured noise

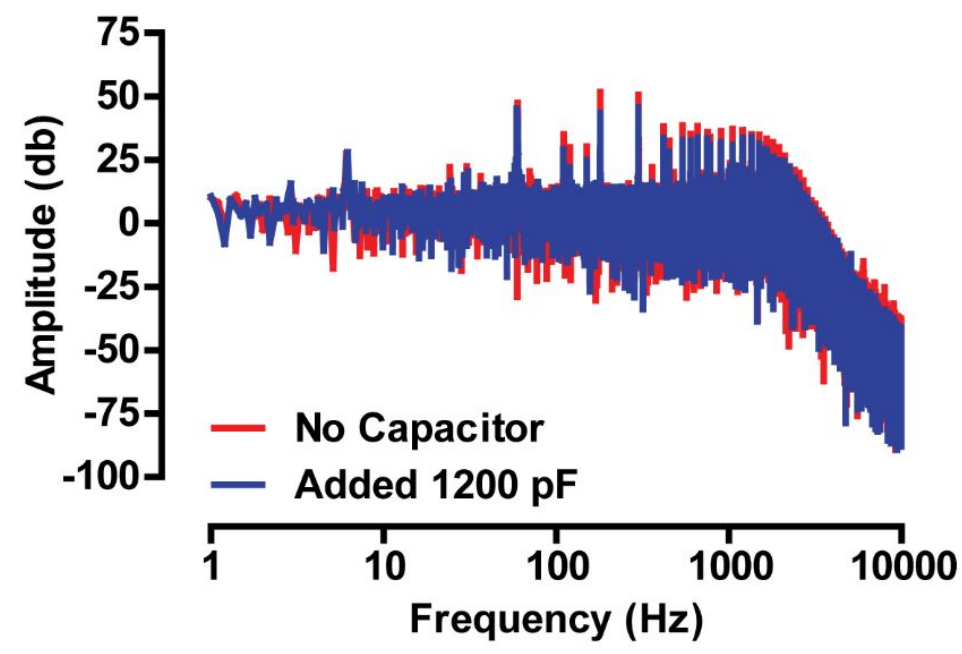

Figure S-1: Comparison of the measured frequency response of the system from 1 to $10 \mathrm{kHz}$ with and without a 1200 pf capacitor added in series to an electrode. The calculated Fourier transform was from a $10 \mathrm{~s}$ recording $0 \mathrm{~V}$ output to an electrode. A decrease can be observed in the overall fast Fourier transform where the $1200 \mathrm{pF}$ capacitor is serving as a high pass filter. 
A. Standard System

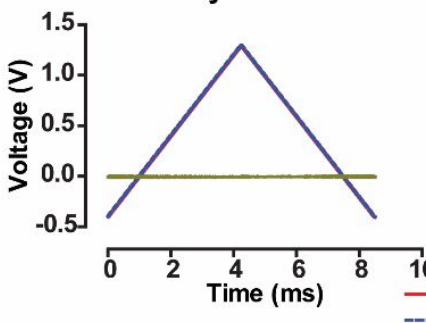

B. Voltage Follower Modified System

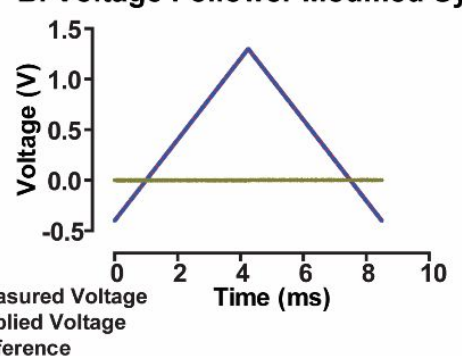

C. Difference of Applied \& Measured WF

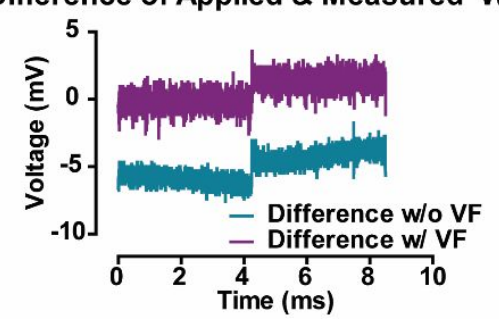

Figure S-2: Comparison of cross talk with and without voltage followers to probe the applied voltage to an electrode. A: A waveform was applied to an electrode, and the applied waveform was recorded (blue) and measured at the electrode interface (red). The difference was tabulated between the two waveforms (yellow). B: Voltage followers were added to the analog inputs of the National Instrument data acquisition card. The applied waveform was again recorded (blue) and probed at the interface (red). The difference was tabulated between the applied and measured interface voltage (yellow). C: The calculated difference between the two measurements was converted to $\mathrm{mV}$ with (turquoise) and without (purple) added voltage followers to the analog input. The medians of the two different measurements significantly differed for the differences in measured signals with and without a voltage follower. $P<0.0001$ Two tailed Mann Whitney Test $n=4250$ pts. 
A. $400 \mathrm{~V} / \mathrm{s}$ WF dopamine measurement

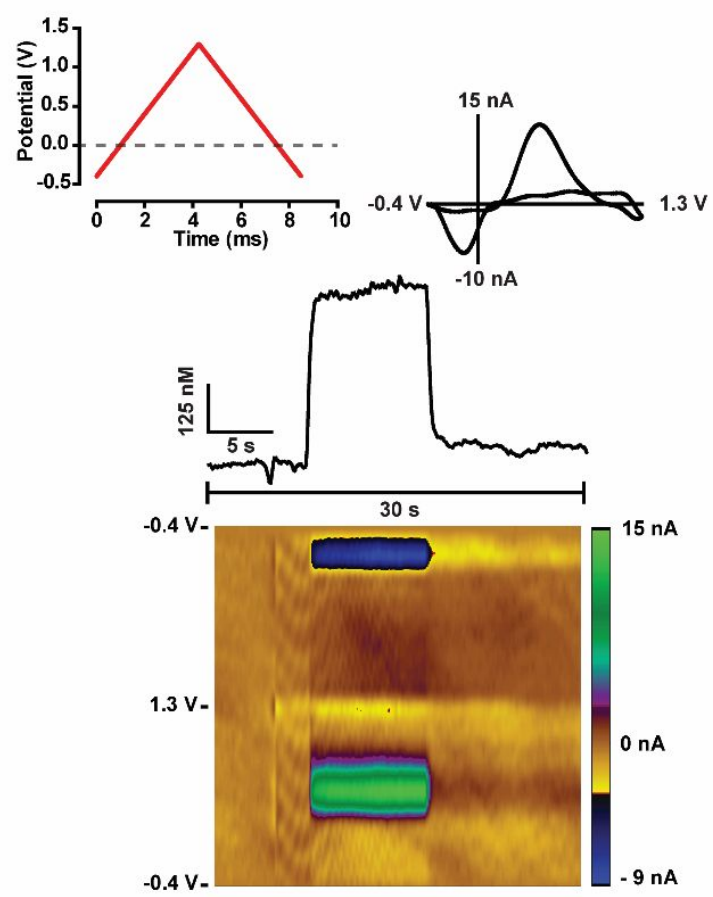

C. CB $1200 \mathrm{~V} / \mathrm{s}$ WF dopamine measurement

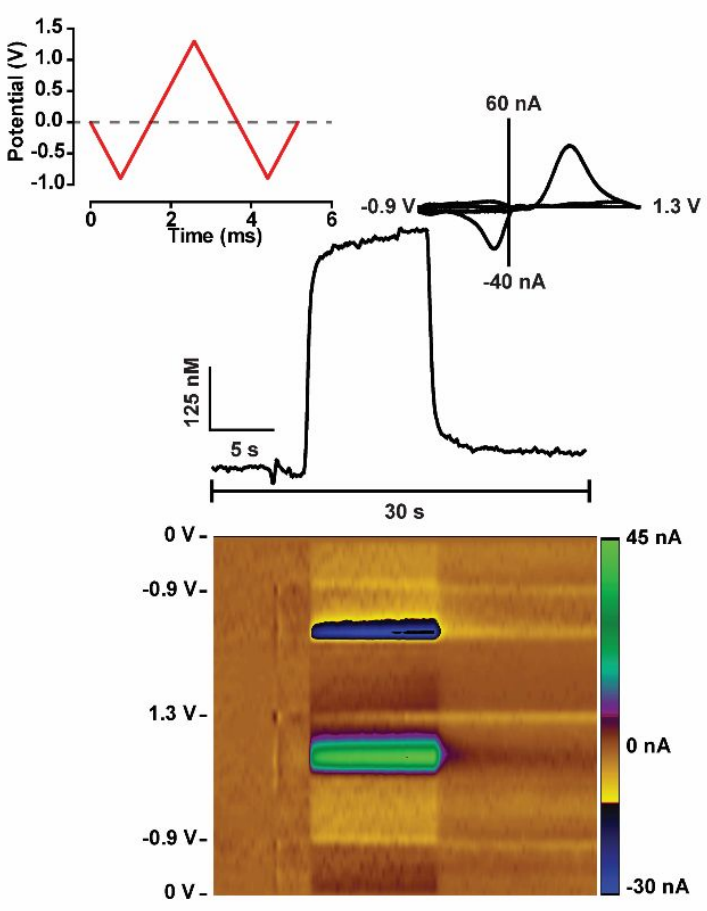

B. $1200 \mathrm{~V} / \mathrm{s}$ WF dopamine measurement

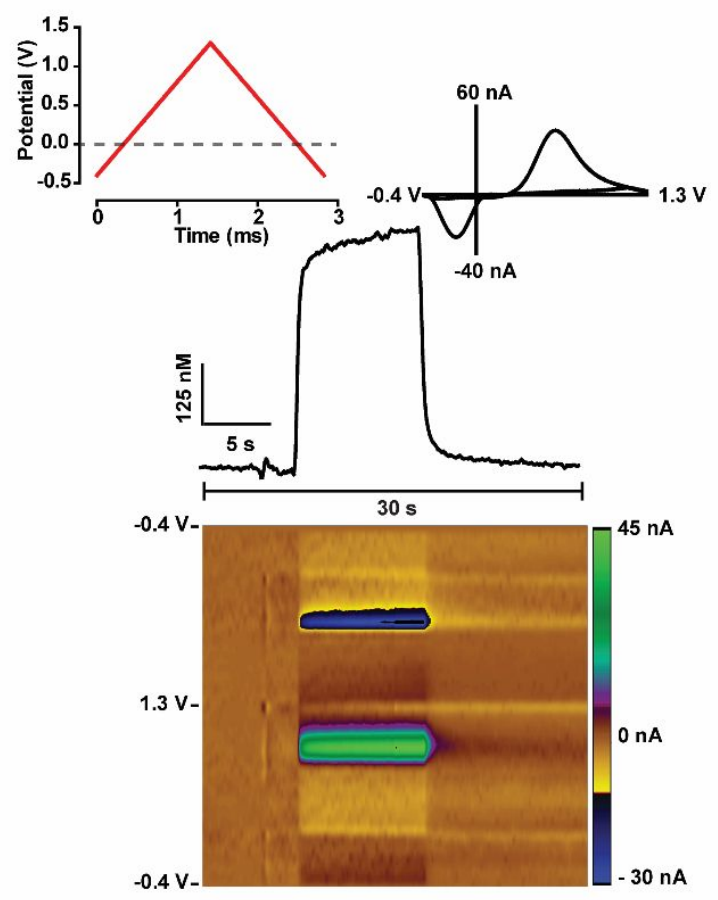

D. $1200 \mathrm{pF} A C$-coupled CB WF measurement of dopamine

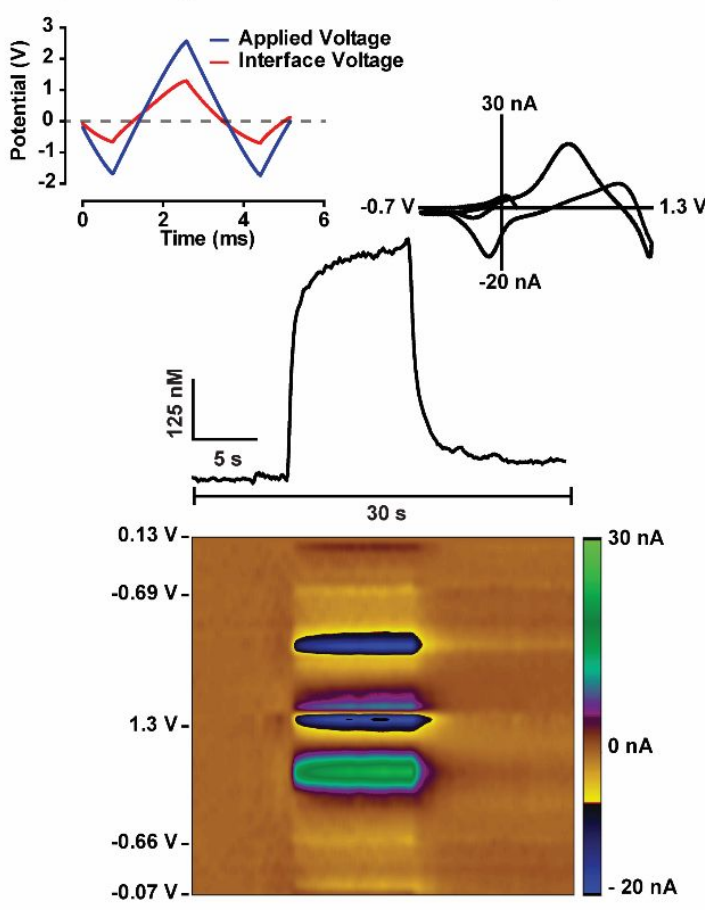

Figure S-3: Application and comparison of four different waveforms for measuring dopamine. Color plots represent $500 \mathrm{nM}$ of dopamine measured with an application frequency applied at $10 \mathrm{~Hz}$ in a pneumatically actuated flow injection system. Event time started at $5 \mathrm{~s}$ and lasted $10 \mathrm{~s}$ for a recording period of $30 \mathrm{~s}$. Current traces were extracted at $0.6 \mathrm{~V}$ and the cyclic voltammogram were taken at $12 \mathrm{~s}$. A: $400 \mathrm{~V} / \mathrm{s}$ waveform applied from $-0.4 \mathrm{~V}$ to $1.3 \mathrm{~V}$ to -0.4 V $400 \mathrm{~V} / \mathrm{s}$. B: $1200 \mathrm{~V} / \mathrm{s}$ waveform applied from $-0.4 \mathrm{~V}$ to $1.3 \mathrm{~V}$ to $-0.4 \mathrm{~V}$ at $1200 \mathrm{~V} / \mathrm{s}$. C: 
Charged balance waveform found by integrating the application waveform at $1200 \mathrm{~V} / \mathrm{s}$ from 0 $\mathrm{V}$ 'to $-0.9 \mathrm{~V}$ to $1.3 \mathrm{~V}$ to $-0.9 \mathrm{~V}$ to $0 \mathrm{~V}$ so that the integral was $0 \mathrm{~V} \cdot \mathrm{s}$. D: AC-coupled measurement of dopamine with $1200 \mathrm{pF}$ added electrode capacitance and a calculated charge-balanced input waveform at $1200 \mathrm{~V} / \mathrm{s}$ from $-0.2 \mathrm{~V}$ to $2.57 \mathrm{~V}$ to $-1.74 \mathrm{~V}$ to $-0.01 \mathrm{~V}$ and measured at the interface to be $-0.08 \mathrm{~V}$ to $-0.66 \mathrm{~V}$ to $1.3 \mathrm{~V}$ to $-0.7 \mathrm{~V}$ to $0.12 \mathrm{~V}$. 

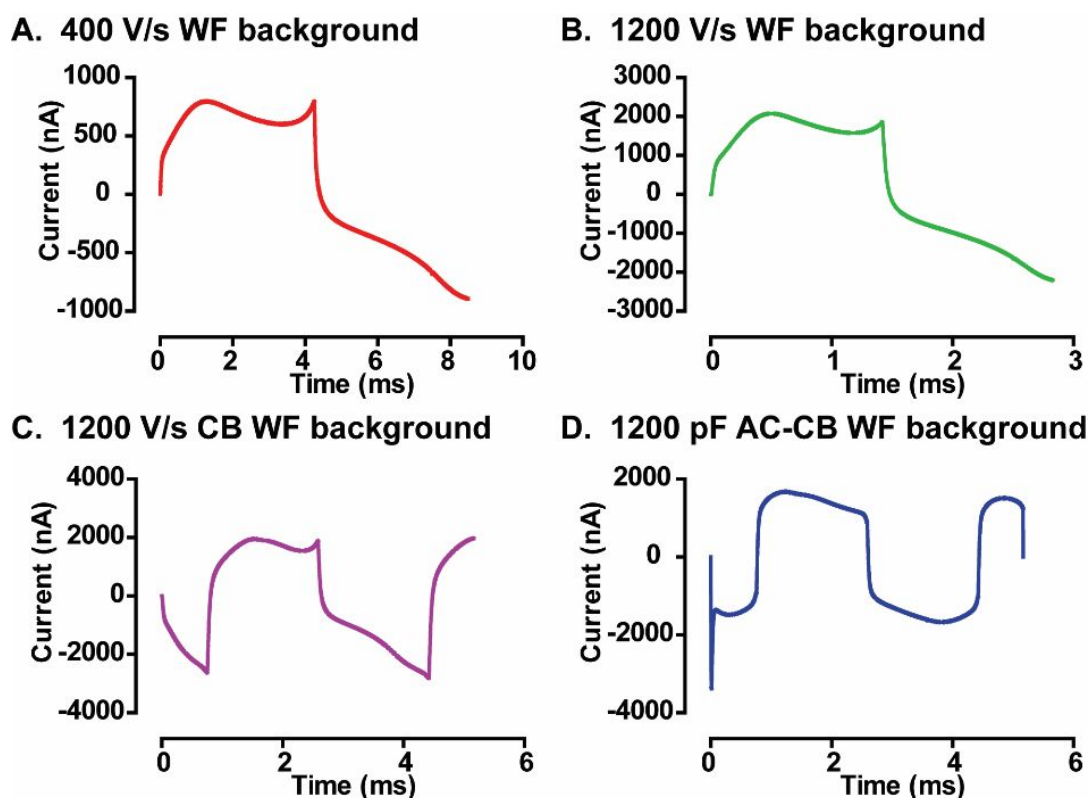

D. $1200 \mathrm{pF}$ AC-CB WF background

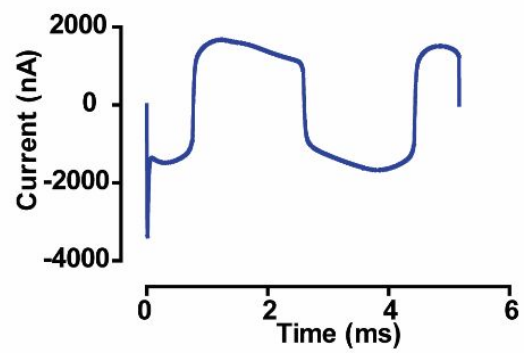

Figure S-4: Selected electrode backgrounds for four various waveforms investigated. A: 400 $\mathrm{V} / \mathrm{s}$ waveform applied at $400 \mathrm{~V} / \mathrm{s}$ from $-0.4 \mathrm{~V}$ to $1.3 \mathrm{~V}$ to $-0.4 \mathrm{~V}$. B: $1200 \mathrm{~V} / \mathrm{s}$ waveform applied from $-0.4 \mathrm{~V}$ to $1.3 \mathrm{~V}$ to $-0.4 \mathrm{~V}$ at $1200 \mathrm{~V} / \mathrm{s}$. C: Charged balanced waveform integrated to $0 \mathrm{~V} \cdot \mathrm{s}$ applied at $1200 \mathrm{~V} / \mathrm{s}$ from $0 \mathrm{~V}$ to $-0.9 \mathrm{~V}$ to $1.3 \mathrm{~V}$ to $-0.9 \mathrm{~V}$ to $0 \mathrm{~V}$. D: AC- Coupled fast scan cyclic voltammetry with $1200 \mathrm{pF}$ added capacitance and charge-balanced templet waveform. 

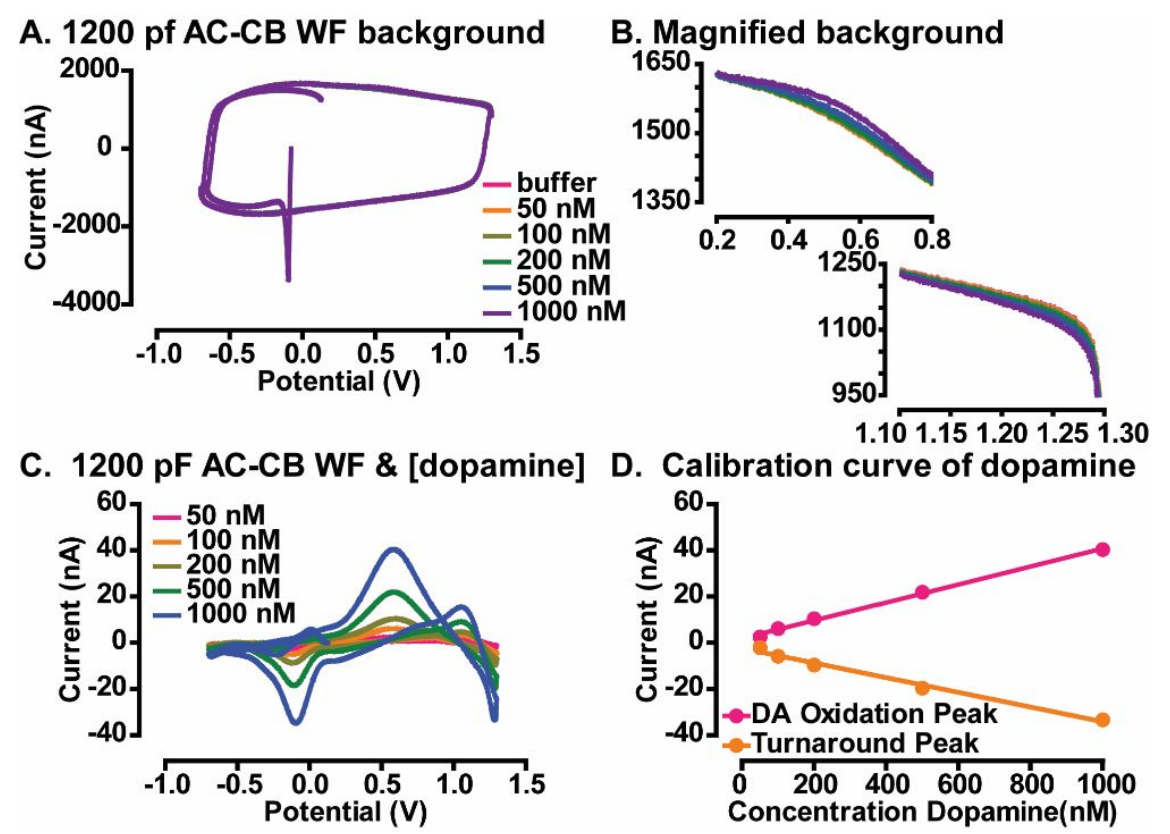

Figure S-5: Dopamine measured with AC-coupled voltammetry comparing background changes. A: Representative background current for different concentrations of dopamine measured with a 1200 pf AC-coupled charge-balanced $1200 \mathrm{~V} / \mathrm{s}$ waveform. B: Enlarged oxidation sweep of representative backgrounds highlighting the distortion of the background at 1.26V. C: Representative dopamine current responses for concentrations spanning $50 \mathrm{nM}$ to $1000 \mathrm{nM}$ of dopamine. D: Calibration curve for dopamine probing the linearity of the oxidation potential (pink) and the dip at the $1.25 \mathrm{~V}$ negative current response (orange). 
A. $400 \mathrm{~V} / \mathrm{s}$ WF $\& \Delta \mathrm{pH}$

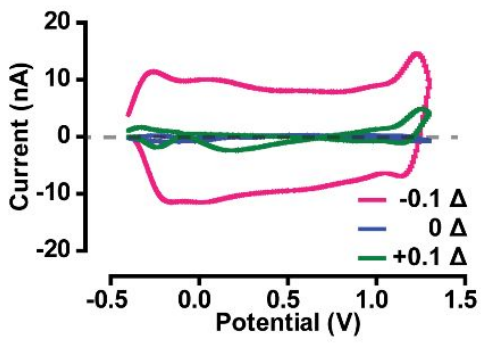

C. $400 \mathrm{~V} / \mathrm{s}$ WF \& $\left[\mathrm{Ca}^{2+}\right]$

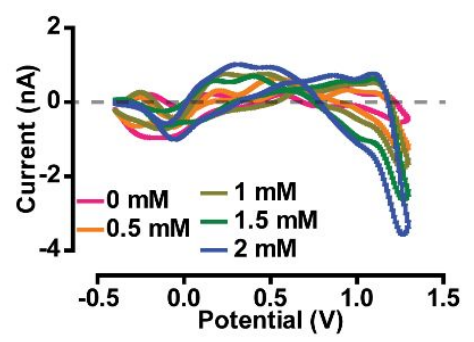

B.1200 pF AC-CB WF \& $\Delta$ pH

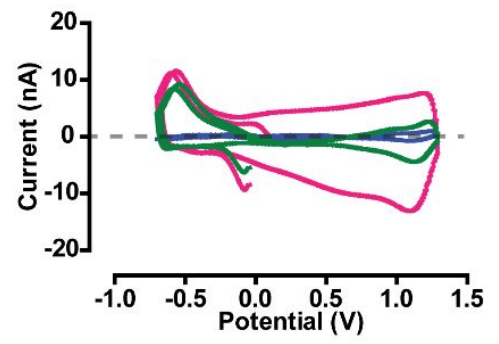

D. $1200 \mathrm{pF}$ AC-CB WF \& $\left[\mathrm{Ca}^{2+}\right]$

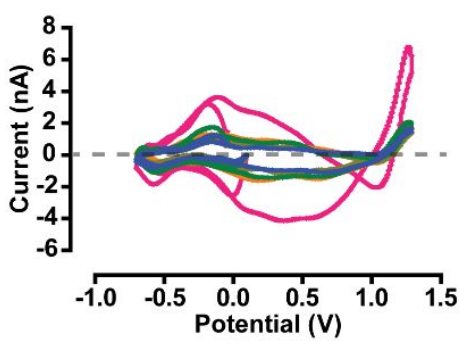

Figure S-6: Effect of $\mathrm{pH}$ and $\left[\mathrm{Ca}^{2+}\right]$ on the measured current response. A: Change in $\mathrm{pH}$ measured with $400 \mathrm{~V} / \mathrm{s}$ waveform and B: AC-coupled charge-balanced waveform with a 1200 $\mathrm{pF}$ capacitor present. $\mathrm{pH}$ was varied from $-0.1 \Delta$ to $+0.1 \Delta \mathrm{pH}$ units. $\mathrm{n}=3$ electrodes. $\mathrm{C}$ : 400 $\mathrm{V} / \mathrm{s}$ waveform was used to measure increasing $\left[\mathrm{Ca}^{2+}\right]$ concentration into artificial cerebral spinal fluid. Calcium was added in addition to the existing $2.4 \mathrm{mM}$ present in the running buffer. D: AC-coupled charge-balanced waveform with a 1200 pF capacitor measuring changing $\left[\mathrm{Ca}^{2+}\right]$ concentrations. $\mathrm{n}=2$ electrodes. 
A. DA \& capacitor comparison

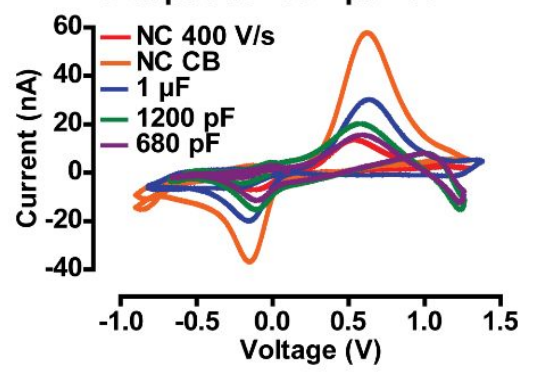

B. FeCOOH \& capacitor comparison

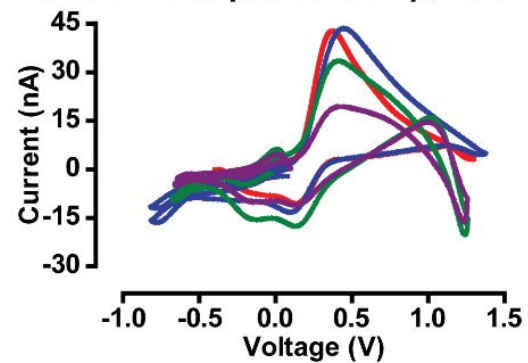

C. $1200 \mathrm{pF}$ AC-CB WF [FeCOOH] comparison

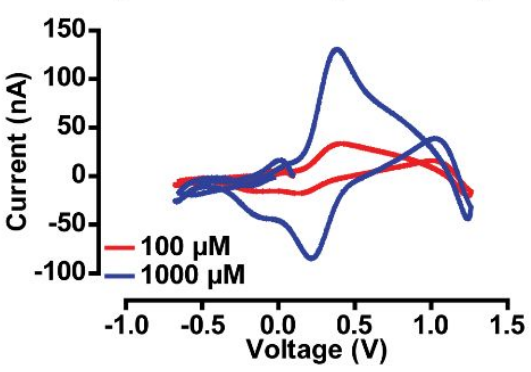

Figure S-7: Comparison of [500 nM] dopamine and [100 $\mu \mathrm{M}]$ ferrocene carboxylic acid with different capacitor values. A: No capacitor (NC $400 \mathrm{~V} / \mathrm{s}$ ) $400 \mathrm{~V} / \mathrm{s}$ waveform was compared with the no capacitor charged balanced $1200 \mathrm{~V} / \mathrm{s}$ (NC CB) waveforms and AC-coupled chargebalanced $1200 \mathrm{~V} / \mathrm{s}$ waveforms with three different capacitor values (680 pF, $1200 \mathrm{pF}, 1 \mu \mathrm{F})$ measuring dopamine. B: Ferrocene carboxylic acid $(\mathrm{FeCOOH})$ was compared with the 400 $\mathrm{V} / \mathrm{s}$ waveform and three capacitor values $(680 \mathrm{pF}, 1200 \mathrm{pF}, 1 \mu \mathrm{F})$ with the AC-coupled chargebalanced input waveform. C: Representative cyclic voltammogram of ferrocene carboxylic acid at $100 \mu \mathrm{M}$ (red) and $1000 \mu \mathrm{M}$ (blue) measured with a $1200 \mathrm{pF}$ capacitor and the ACcoupled charged balanced $1200 \mathrm{~V} / \mathrm{s}$ input waveform. 
A. $400 \mathrm{~V} / \mathrm{s}$ WF \& $500 \mathrm{nM}$ 5-HT measurement
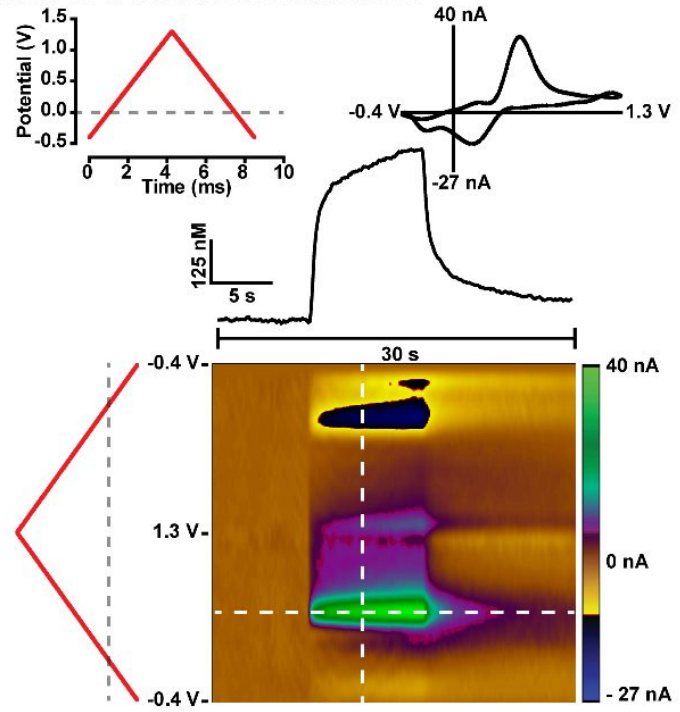

C. $400 \mathrm{~V} / \mathrm{s}$ WF \& $20 \mu \mathrm{M}$ DOPAC measurement

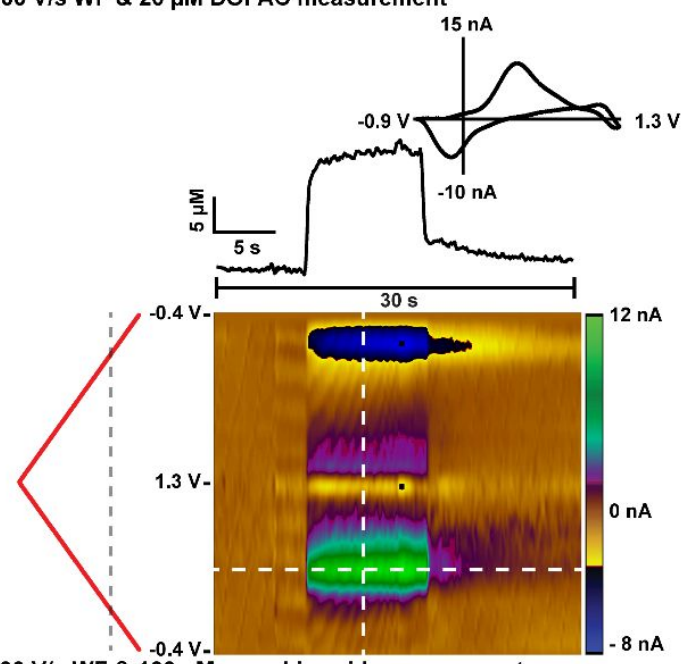

E. $400 \mathrm{~V} / \mathrm{s}$ WF $\& 100 \mu \mathrm{M}$ ascorbic acid measurement

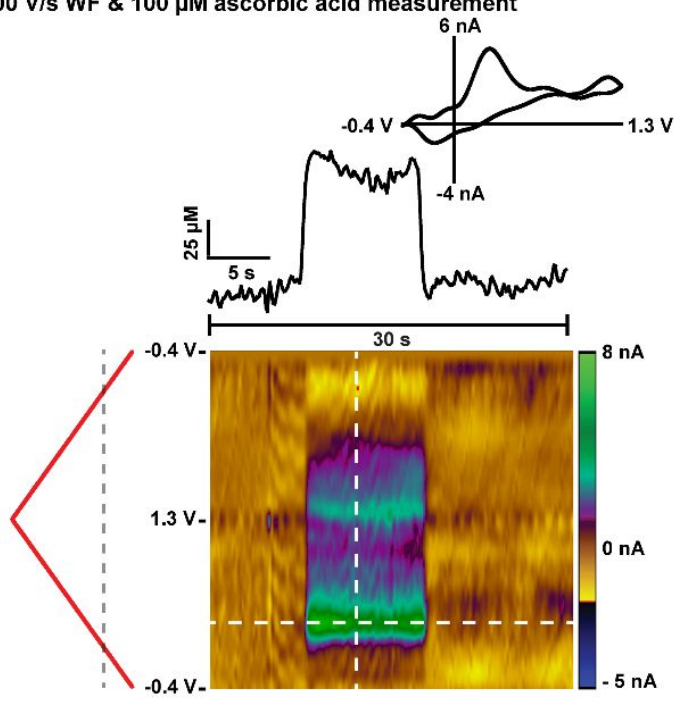

B. 1200 pF AC-CB WF $\& 500$ nM 5-HT measurement

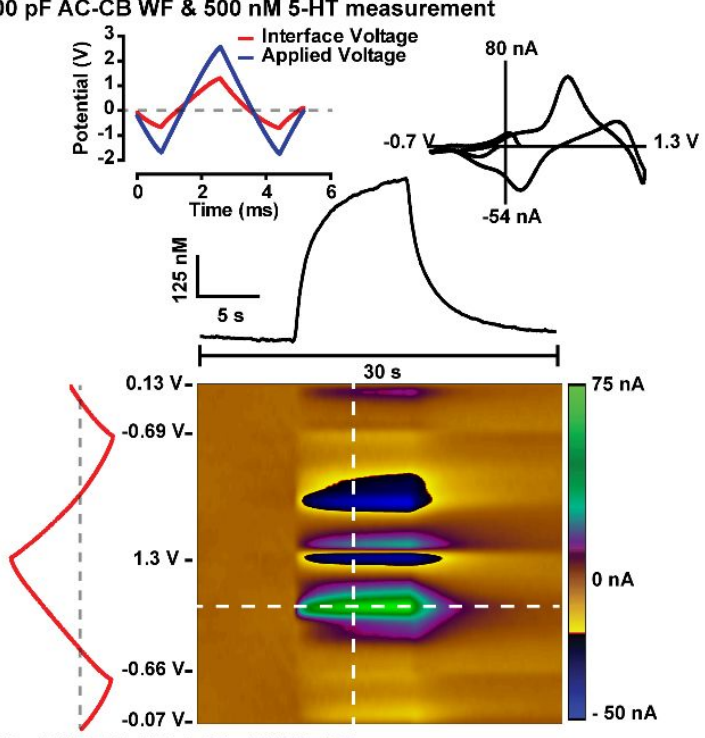

D. $1200 \mathrm{pF}$ AC-CB WF \& $20 \mu \mathrm{M}$ DOPAC measurement

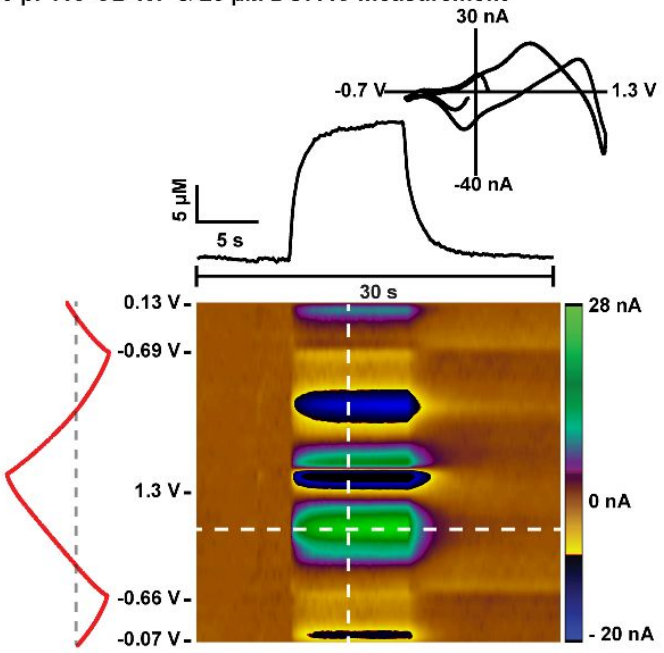

F. $1200 \mathrm{pF}$ AC-CB WF \& $100 \mu \mathrm{M}$ ascorbic acid measurement

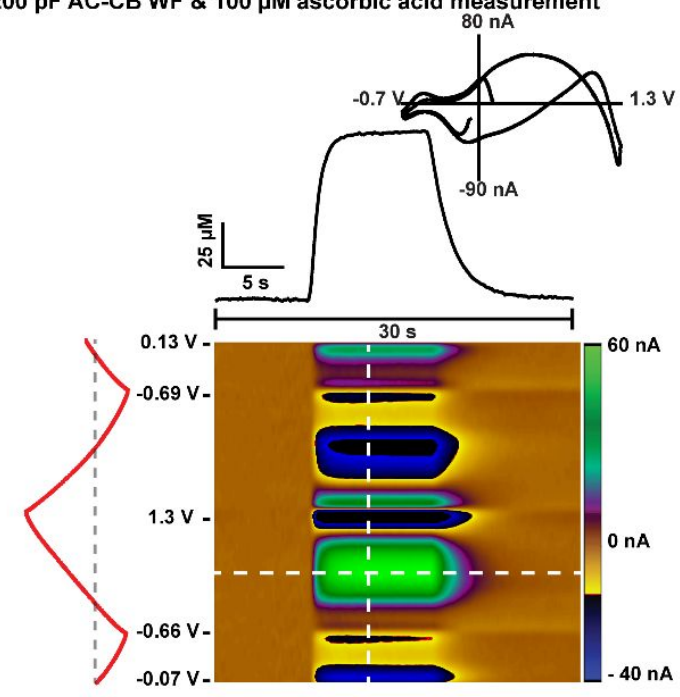


Figure S-8: Application and comparison of the $400 \mathrm{~V} / \mathrm{s}$ waveform (Left) with the $1200 \mathrm{pF}$ ACcoupled charged balanced $1200 \mathrm{~V} / \mathrm{s}$ waveform (Right). A/B: $500 \mathrm{nM}$ serotonin (5-HT), C/D: $20 \mu \mathrm{M}$ 3,4-Dihydroxyphenylacetic acid (DOPAC) and E/F: $100 \mu \mathrm{M}$ ascorbic acid (AA). Application frequency was recorded at $10 \mathrm{~Hz}$ and neurotransmitters were measured in a pneumatically actuated flow injection system. Event time started at $5 \mathrm{~s}$ and lasted $10 \mathrm{~s}$ for a recording period of $30 \mathrm{~s}$. Current traces were extracted at $0.6 \mathrm{~V}$ and the cyclic voltammograms were taken at $12 \mathrm{~s}$. Figure S-8: Application and comparison of the $400 \mathrm{~V} / \mathrm{s}$ waveform (Left) with the $1200 \mathrm{pF}$ AC-coupled charged balanced $1200 \mathrm{~V} / \mathrm{s}$ waveform (Right). A/B: $500 \mathrm{nM}$ serotonin (5-HT), C/D: $20 \mu \mathrm{M}$ 3,4-Dihydroxyphenylacetic acid (DOPAC) and E/F: $100 \mu \mathrm{M}$ ascorbic acid (AA). Application frequency was recorded at $10 \mathrm{~Hz}$ and neurotransmitters were measured in a pneumatically actuated flow injection system. Event time started at $5 \mathrm{~s}$ and lasted $10 \mathrm{~s}$ for a recording period of $30 \mathrm{~s}$. Current traces were extracted at $0.6 \mathrm{~V}$ and the cyclic voltammograms were taken at $12 \mathrm{~s}$. 
A. $400 \mathrm{~V} / \mathrm{s}$ waveform 500 nM Dopamine

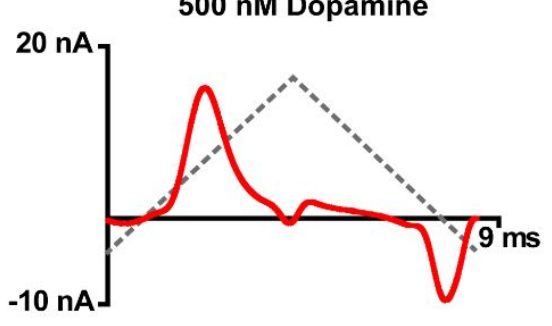

$500 \mathrm{nM} 5-\mathrm{HT}$

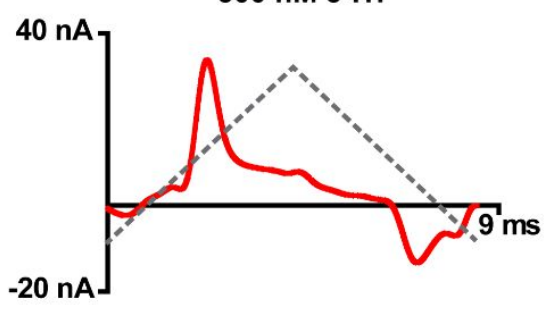

$20 \mu M$ DOPAC

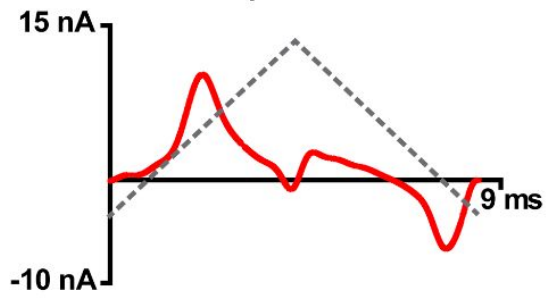

$100 \mu \mathrm{M}$ Ascorbic Acid

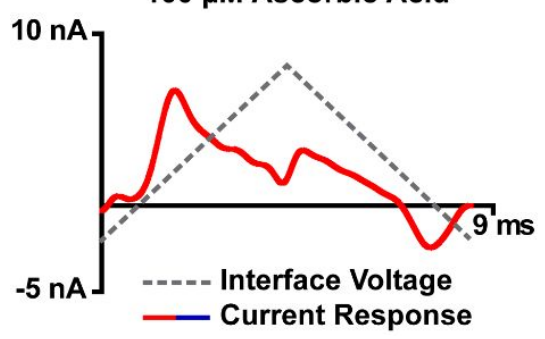

B. $1200 \mathrm{pF}$ AC-CB waveform

500 nM Dopamine

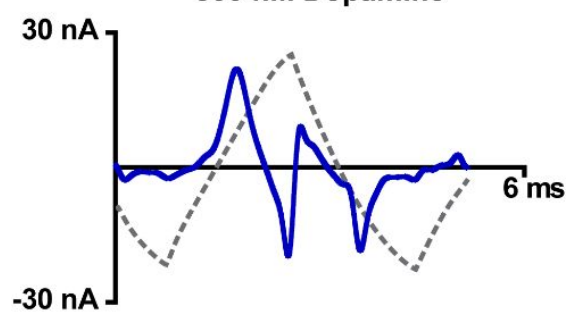

$500 \mathrm{nM} 5-\mathrm{HT}$

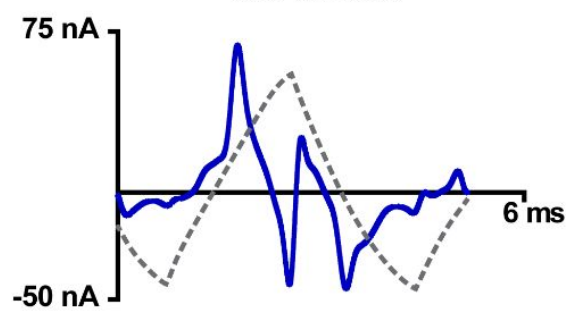

$20 \mu M$ DOPAC
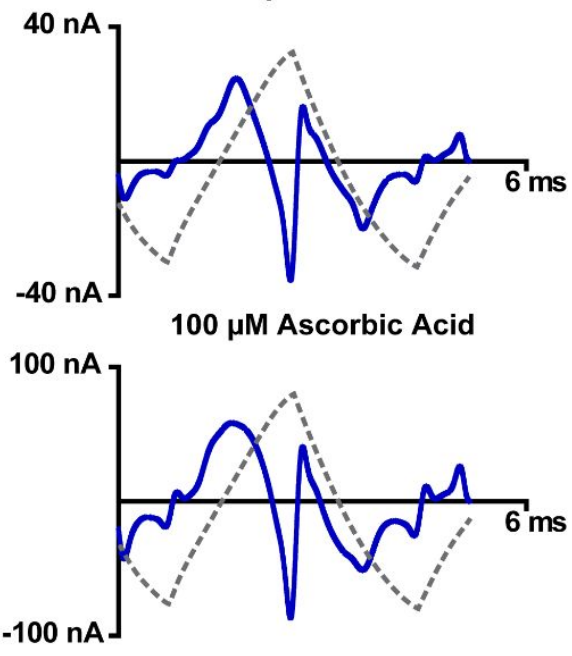

Figure S-9: Unfolded cyclic voltammograms of dopamine, serotonin (5-HT), 3,4Dihydroxyphenylacetic acid (DOPAC), and ascorbic acid comparing the standard dopamine waveform (Left) and the 1200 pf AC-coupled charged balanced $1200 \mathrm{~V} / \mathrm{s}$ waveform (Right). Time is reported in ms, and interface voltage sweep corresponding to the timing of the current response is highlighted in grey. 
A. Dopamine

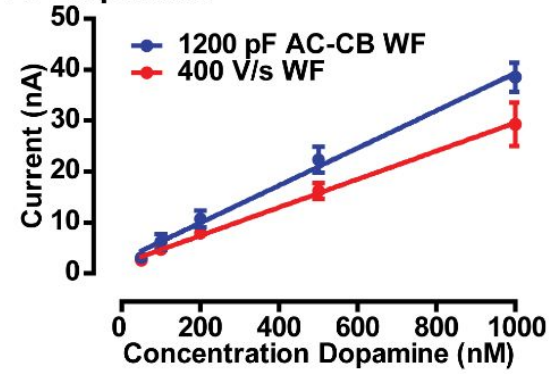

C. 5-HT

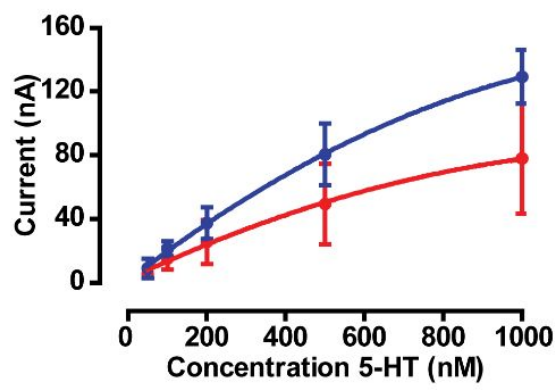

B. DOPAC

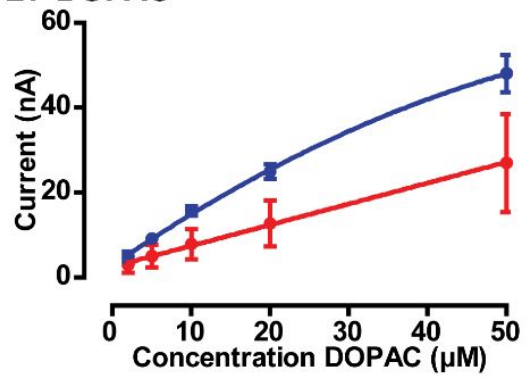

D. Ascorbic Acid

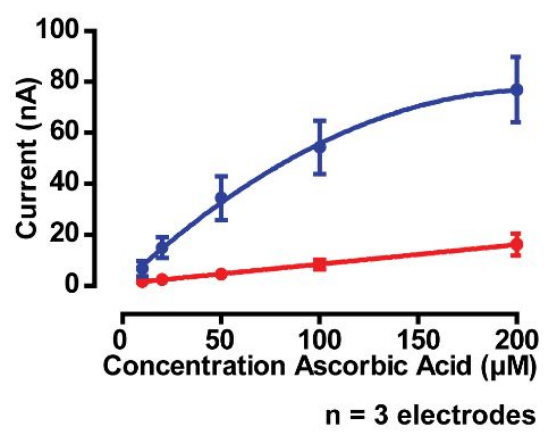

Figure S-10: Calibration curves of dopamine, 3,4-Dihydroxyphenylacetic acid (DOPAC), serotonin (5-HT) and ascorbic acid using $400 \mathrm{~V} / \mathrm{s}$ (red) and AC-coupled charge-balanced waveform with a $1200 \mathrm{pF}$ capacitor added in series (Blue). A: Dopamine $400 \mathrm{~V} / \mathrm{s} \mathrm{r}^{2}=0.998$, AC-coupled charge-balanced $r^{2}=0.994$, B: DOPAC $400 \mathrm{~V} / \mathrm{s} \mathrm{r}^{2}=0.998$, AC-coupled chargebalanced $r^{2}=0.985$, C: $5-\mathrm{HT} 400 \mathrm{~V} / \mathrm{s} r^{2}=0.709$, AC-coupled charge-balanced $r^{2}=0.946, \quad D$ : ascorbic acid $400 \mathrm{~V} / \mathrm{s} r^{2}=0.995$, AC-coupled charge-balanced $r^{2}=0.928$. Linear regression curves were used for dopamine with $400 \mathrm{~V} / \mathrm{s}$ waveform, dopamine with AC-coupled chargebalanced waveform, DOPAC with $400 \mathrm{~V} / \mathrm{s}$ waveform, and ascorbic acid with $400 \mathrm{~V} / \mathrm{s}$ waveform. Nonlinear second order polynomial fits were used for the remaining calibration curves. Each electrode calibration point was measured in pseudo triplicate. ( $n=3$ electrodes, $\pm S D$ ) 


\section{References:}

(1) Vreeland, R. F.; Laude, N. D.; Lambert, S. M.; Heien, M. L. Microwave-Plasma Dry-Etch for Fabrication of Conducting Polymer Microelectrodes. Anal. Chem. 2014, 86 (3), 13851390. https://doi.org/10.1021/ac403363a.

(2) Ungerstedt, U. Introduction to Intracerebral Microdialysis. Tech. Behav. Neural Sci. 1991, 7, 3-22. https://doi.org/10.1016/B978-0-444-81194-3.50006-X.

(3) Heien, M. L. A. V; Khan, A. S.; Ariansen, J. L.; Cheer, J. F.; Phillips, P. E. M.; Wassum, K. M.; Wightman, R. M. Real-Time Measurement of Dopamine Fluctuations after Cocaine in the Brain of Behaving Rats. Proc. Natl. Acad. Sci. U. S. A. 2005, 102 (29), 1002310028. https://doi.org/10.1073/pnas.0504657102.

(4) Vreeland, R. F.; Atcherley, C. W.; Russell, W. S.; Xie, J. Y.; Lu, D.; Laude, N. D.; Porreca, F.; Heien, M. L. Biocompatible PEDOT:Nafion Composite Electrode Coatings for Selective Detection of Neurotransmitters in Vivo. Anal. Chem. 2015, 87 (5), 2600-2607. https://doi.org/10.1021/ac502165f.

(5) Diedenhofen, B.; Musch, J. Cocor: A Comprehensive Solution for the Statistical Comparison of Correlations. PLoS One 2015, 10 (4), e0121945.

https://doi.org/10.1371/journal.pone.0121945. 